\title{
Severe dolichoectasia of the intracranial arteries
}

\author{
Jelle Vandersteene $\cdot$ Patrick Santens
}

Received: 29 October 2011/Accepted: 13 January 2012/Published online: 1 March 2012

(C) Belgian Neurological Society 2012

A 74-year-old man presented with a progressive gait disorder, mental impairment and urinary incontinence. MRI showed enlarged lateral ventricles and dolichoectasia of vertebrobasilar and carotid arteries, with prominent compression of the lower brainstem. An evacuative lumbar puncture improved the symptoms only marginally.

The most common clinical presentations of dilatative arteriopathy include acute brain ischemia and progressive compression of cranial nerves [1], and less frequently gait ataxia, pseudo-parkinsonism and cognitive impairment [2]. A possible explanation for the enlarged ventricles is the basilar artery lifting the floor of the third ventricle [1]. Figure. 1.

\section{Conflict of interest None.}

\section{References}

1. Lou M, Caplan LR (2010) Vertebrobasilar dilatative arteriopathy (dolichoectasia). Ann N Y Acad Sci 1184:121-133

2. Smoker WR, Corbett JJ, Gentry LR, Keyes WD, Price MJ, McKusker S (1986) High-resolution computed tomography of the basilar artery: 2. Vertebrobasilar dolichoectasia: clinical-pathologic correlation and review. AJNR Am J Neuroradiol 7(1):61-72

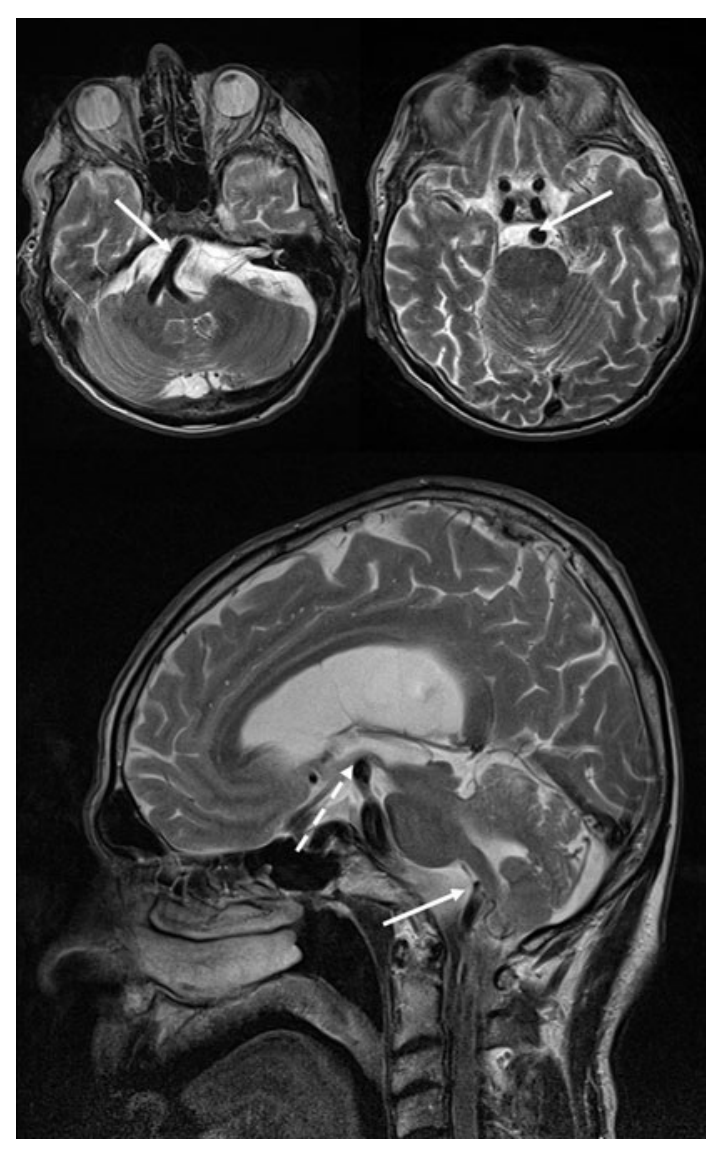

Fig. 1 Dolichoectasia of the intracranial arteries. Note the dolichobasilar artery compressing and displacing the medulla oblongata (straight arrow) and lifting the floor of the third ventricle (dashed arrow)

J. Vandersteene $(\bowtie) \cdot$ P. Santens

Department of Neurology, Gent University Hospital,

Gent, Belgium

e-mail: jelle.vandersteene@ugent.be 